\title{
Considerações sobre um campo disciplinar: os principais modelos explicativos da economia colonial
}

Considerations on a disciplinary field: The main explanatory models of the colonial economy

\author{
Eduardo Jose Santos Borges* \\ Augusto Fagundes da Silva dos Santos ${ }^{* *}$
}

\begin{abstract}
Resumo
O presente artigo tem como objetivo fundamental trazer, de forma balanceada, os principais teóricos e teorias acerca das características essenciais da Economia Colonial e da Formação Econômica do Brasil. O leitor terá a oportunidade de conhecer, mesmo que introdutoriamente, parte da historiografia econômica brasileira do século XX até os dias atuais e perceber os aspectos mais relevantes de cada modelo explicativo. Ao dispor-se a examinar a evolução do pensamento interpretativo da economia brasileira sob o ponto de vista da historiografia, esse artigo também se propõe em colocar-se enquanto instrumento auxiliar no processo ensino-aprendizagem dos cursos de graduação em História e Ciências Econômicas, principalmente para as disciplinas de História do Brasil Colônia e Formação Econômica do Brasil.
\end{abstract}

Palavras-chave: Historiografia; Economia colonial; Formação econômica do Brasil.

\begin{abstract}
This article has as its fundamental objective to bring in a balanced way the main theorists and theories about the essential characteristics of the Colonial Economy and the Economic Formation of Brazil. The reader will have the opportunity to know, even if in an introductory way, much of the Brazilian economic historiography of the twentieth century until the present day. And it will present the most relevant aspects of each explanatory model. In preparing to examine the evolution of the interpretive thinking of the Brazilian economy from the point of view of historiography, this article also proposes to put itself as an auxiliary instrument in the teaching-learning process of undergraduate courses in History and Economic Sciences, mainly for the subjects of History of Brazil Colony and Economic Formation of Brazil.
\end{abstract}

Keywords: Historiography; Colonial economy; Economic formation of Brazil.

\section{Introdução}

Entender o complexo processo de ocupação do espaço americano pelo Império português pressupõe admitir que tal fenômeno se deu no contexto de uma história que não se restringia exclusivamente à América ou ao reino lusitano, mas às transformações ocorridas no Antigo Regime europeu. Contudo, a dinâmica interna do reino português,

\footnotetext{
* Doutor em História Social pela Universidade Federal da Bahia (UFBA). Professor da Universidade do Estado da Bahia (UNEB).

** Doutorando em História pela Universidade Federal da Bahia (UFBA). Professor da Universidade Estadual de Feira de Santana (UEFS).
}

Recebido em outubro de 2017 | Aprovado em fevereiro de 2018. 
com uma cultura política e social tecida em anos de construção e consolidação da nação e do Estado, não pode ser negligenciada nesse processo de entendimento.

As ações estratégicas engendradas pelo Império português na dinâmica de ocupação, domínio e exploração de suas colônias, devem ser analisadas sob um ponto de vista dialético na medida em que se deve levar em conta tanto o movimento expansionista europeu quanto a própria transformação interna da sociedade portuguesa.

Partindo desse pressuposto, entender a dinâmica da economia colonial em termos de interpretação historiográfica, significa se aproximar das duas vertentes de análise acima identificadas. De um lado, uma perspectiva que fomenta um exame teórico, tendendo a enquadrar a existência da América colonial portuguesa no interior de um sistema colonial de exploração. Nesse caso, trata-se de uma análise até certo ponto estruturante, cuja dinâmica socioeconômica do Brasil colonial foi ditada pela lógica de funcionamento do sistema econômico europeu, sendo Portugal, uma parte integrante e periférica desse sistema. Em boa parte do século XX, essa foi a chave interpretativa de setores importantes da historiografia brasileira.

Por outro lado, a partir dos anos 1980 e 1990 do século passado, a historiografia vivenciou uma transformação e renovação nos seus objetos e abordagens, conduzindo a uma vertente de análise que pretendia ultrapassar a visão dicotômica identificada na oposição metrópole/colônia, tornando mais complexa a relação entre ambas. Sem necessariamente negar a existência de uma centralidade de poder representada pela força centrípeta da metrópole, essa historiografia entende a colônia americana não apenas como parte periférica e submissa à um sistema superior, mas uma participante direta de um sistema político-administrativo de dimensão imperial.

Mais do que fomentar conflitos, entendemos que esse debate de ideias enriqueceu o olhar historiográfico sobre nosso passado colonial, tornando-o mais complexo e, principalmente, ressaltando a dimensão plural que caracterizou as conexões entre as diversas partes que compunham o Império português. O desafio, nas páginas que se seguem, é adentrar nesse debate e apontar algumas possibilidades de análises que possam motivar a continuidade de tão salutar discussão no campo historiográfico, além de oferecer, de forma balanceada, um material que funcione como ferramenta de reflexão crítica para os cursos de graduação em História e em Ciências Econômicas. 


\section{A Escola do Sentido da Colonização}

Preocupado em diagnosticar os problemas brasileiros de sua época, tais como retardo econômico, defasagem tecnológica, desigualdade social, dentre outras questões, Caio Prado Jr. buscou as respostas na formação histórica do capitalismo. Durante as décadas de 1930 e 1940, o autor, no maturar de suas ideias, escreveu o livro "Evolução Política do Brasil" (1933) e, na década seguinte, elaborou o clássico "Formação do Brasil Contemporâneo" (1942). Em ambos é possível observar a ideia de uma economia colonial visceralmente vinculada ao capitalismo em formação, ou seja, a colônia não seria um organismo autônomo montado a partir de suas relações internas, pelo contrário, era parte de uma realidade mais ampla (o comércio europeu). Segue trecho em que o autor justifica essa perspectiva de análise:

[...] todos os grandes acontecimentos desta era a que se convencionou com razão chamar de "descobrimentos", articulam-se num conjunto que não é senão um capítulo da história do comércio europeu. Tudo que se passa são incidentes da imensa empresa comercial a que se dedicam os países da Europa a partir do séc. XV e que lhes alargará o horizonte pelo oceano afora. Não tem outro caráter a exploração da costa africana e o descobrimento e a colonização das ilhas pelos portugueses, o roteiro das Índias, o descobrimento da América, a exploração e ocupação de seus vários setores (PRADO JR., 1977, p. 22).

A organização e a exploração da empresa colonial possuíam uma razão, "o sentido da colonização". Essa é a categoria analítica básica que permeia todo o pensamento pradiano, por conta disso, em toda a sua obra, jamais o fenômeno da colonização do Brasil será tratado como algo casual ou circunstancial, pelo contrário, a ideia de "Sentido" propõe uma intencionalidade que, no caso da colônia, seria de produzir e oferecer gêneros tropicais complementares à economia europeia:

Todo povo tem na sua evolução, vista à distância, um certo "sentido". Este se percebe não nos pormenores de sua história, mas no conjunto dos fatos e acontecimentos essenciais que a constituem num largo período de tempo (PRADO JR., 1977, p. 19).

Após a introdução do conceito-chave, Caio Prado Jr. apresenta as características básicas que fundamentavam a vida material da colônia: a grande propriedade monocultora e a utilização em larga escala de mão-de-obra escrava amplamente voltada para o mercado externo. Tratando esses elementos como essenciais, outras temáticas como a pequena e a média propriedade, a economia de subsistência e o mercado interno 
aparecem apenas como atividades subsidiárias, tendo as suas dinâmicas totalmente atreladas à economia de exportação:

\begin{abstract}
Além das atividades fundamentais [...] poderíamos acrescentar outras, como a pecuária, certas produções agrícolas, em suma aquelas atividades que não tem por objetivo o comércio externo [...] não podemos colocá-las no mesmo plano, pois pertencem a outra categoria, e categoria de segunda ordem. Tratase de atividades de subsidiárias destinadas a amparar e tornar possível a realização das primeiras. Não tem uma vida própria, autônoma, mas acompanham aquelas, a que se agregam como simples dependências (PRADO JR., 1977, p. 124).
\end{abstract}

Considerando o contexto/período em que produziu a maioria de seus trabalhos e as dificuldades inerentes a eles, consideramos injusta algumas críticas feitas a Caio Prado Jr., como por exemplo, a "acusação" de ter sido um teleológico. Escrevendo na primeira metade do século XX e partindo de um "momento preciso, já muito adiantado" (PRADO JR., 1977, p. 20) da história do Brasil, o final do período colonial, o que ele encontra em ambos os contextos é um país ocupando posição semelhante no cenário econômico internacional, ou seja, uma economia subsidiária, complementar, fornecedora de matérias-primas e de produtos de primeira necessidade às potências capitalistas. Portanto, a adoção do conceito de "sentido" não surge a priori como necessidade básica de sua narrativa, pelo contrário, é resultado das indagações e constatações as quais chega, o autor, a partir de suas observações enquanto sujeito inserido na realidade econômico-social brasileira de seu tempo presente (Brasil das primeiras décadas do século XX).

Da mesma forma, a pequena e média propriedade e o mercado interno não foram negados pelo historiador. Sobre a primeira, ele afirma que, diante da plantation escravista, a pequena e média propriedade não encontrou espaço para se desenvolver e, sobre o segundo, considerou que o mercado interno era limitado. Lendo, minuciosamente, a obra de Caio Prado Jr., fica evidente que essas lacunas não são resultado de ignorância ou negligência ${ }^{1}$, mas decorrentes do estilo ensaístico adotado que privilegia uma análise macroestrutural - a dinâmica de funcionamento da economia colonial vinculada ao capital mercantil europeu - o que acabou, obrigatoriamente, deixando para segundo plano demais questões como, por exemplo, a intensidade do mercado interno. Aliás, criticar um autor que escreveu a maior parte de seus trabalhos nas décadas de 1930 e 1940, um dos pioneiros no esforço em escrever uma história

\footnotetext{
${ }^{1}$ Em algumas passagens do livro, "Formação do Brasil Contemporâneo", o autor se refere à existência de um mercado interno, a exemplo da página 125 da $15^{\text {a }}$ edição publicada em 1977.
} 
econômica do Brasil. Um pesquisador, portanto, que influenciou uma legião de estudiosos da segunda metade do século $\mathrm{XX}$, ser julgado apenas pelo fato de ter posto a questão do mercado interno para segundo plano, a nosso ver, é injusto. Além da opção metodológica e das questões de enfoque e abordagem já mencionadas, deve-se considerar a dificuldade de acesso às fontes na época e a ausência de trabalhos monográficos regionais com forte valor empírico que só ganhariam força em fins da década de 1970 com a proliferação dos programas de pós-graduação. Como em todo o trabalho de vanguarda, as lacunas são inevitáveis e "saudáveis" para o desenvolvimento do conhecimento histórico.

Dando certa continuidade às teses de Caio Prado Jr., vale mencionar os escritos do economista Celso Furtado que impulsionado pelo movimento em torno da criação da CEPAL - Comissão Econômica para a América Latina -, ao publicar, em 1959, o livro "Formação Econômica do Brasil". As conclusões do autor em relação à formação econômica do Brasil e sua posição no mercado internacional são convergentes às ideias de Caio Prado Jr., ou seja, também para Furtado, a economia colonial era parte integrante de algo mais amplo (a economia mercantil europeia), extremamente depende do mercado externo e com ínfimo grau de autonomia. Podemos observar essas afirmações na citação a seguir:

Sendo uma grande plantação de produtos tropicais, a colônia estava intimamente integrada nas economias europeias, das quais dependia. Não constituía, portanto, um sistema autônomo, sendo simples prolongamento de outros maiores (FURTADO, 1975, p. 95).

Esse autor foi inovador no que tange à introdução de conceitos puramente econômicos sem perder de vista o processo histórico. A partir de conceitos como, "produção", "distribuição" e "fluxo de renda", o autor analisa a formação econômica do Brasil desde a economia colonial até a economia industrial.

A principal conclusão de Furtado sobre a economia colonial é que o principal responsável pelo retardo econômico brasileiro foi a economia escravista agroexportadora. Segundo ele, a produção extensiva possibilitada pelas vastas proporções territoriais com utilização em larga escala de mão-de-obra escravizada dificultou o progresso tecnológico, além disso, o direcionamento para o mercado externo associado à escassez de renda monetária limitava o desenvolvimento do mercado interno. Para Furtado, o tripé pradiano (monocultura para exportação, grande propriedade e mão de obra escrava) promoveu grande concentração de renda tanto entre 
os grupos sociais quanto entre as diferentes regiões do Brasil, beneficiando as regiões produtoras de artigos em alta no mercado internacional.

Excetuando os conceitos técnicos das Ciências Econômicas, em que Celso Furtado inovou em relação ao modelo pradiano? A inovação no estudo das flutuações da economia colonial. Partindo das mesmas premissas, como já dissemos anteriormente, a falta de autonomia da economia colonial, que, segundo ele, era totalmente dependente das flutuações do mercado internacional, o autor constata que nos períodos de alta de preços no cenário externo das mercadorias de exportação, a plantation escravista aumentava a demanda por produtos para seu abastecimento, estimulando, assim, o mercado interno. Já nos períodos de deflação nos preços dos principais itens de exportação, ocorria justamente o inverso, ou seja, o dinamismo do mercado interno se reduzia. A justificativa para essa ação se dava pelo fato de que a atividade principal da economia colonial diminuía sua demanda, reduzindo as compras dos produtos de subsistência, passando ela mesma a produzi-los através do deslocamento de parte do contingente de mão de obra escravizada ociosa da lavoura de exportação para a produção de subsistência.

Para fechar o "ciclo" de autores da Escola do "Sentido da Colonização", destacamos Fernando Antonio Novais que, em 1979, publicou "Portugal e Brasil na Crise do Antigo Sistema Colonial, 1777-1808”. Entendemos que Novais sofisticou o pensamento pradiano. Por meio da introdução do conceito do Antigo Sistema Colonial, ou seja, resultante da expansão marítimo-comercial das nações europeias nas sociedades do Antigo Regime, o autor demonstrou as vantagens do ponto de vista econômico dessas metrópoles com as suas respectivas colônias, focalizando, em particular, as relações entre Portugal e Brasil dentro desta estrutura. As metrópoles enquadraram as áreas colonizadas através dos instrumentos da política econômica mercantilista da época, o exclusivo metropolitano, que, para o autor, se constituiu como peça-chave dentro da "engrenagem" denominada sistema colonial. Esse sistema, através dos seus vários instrumentos, incluindo o "pacto" ou "exclusivo colonial", desempenhou papel fundamental no processo de acúmulo primitivo de capitais no período moderno, etapa necessária ao surgimento do capitalismo industrial na Europa. Vejamos como Novais conceituou o Sistema Colonial:

Numa primeira aproximação, o sistema colonial apresenta-se-nos como o conjunto das relações entre as metrópoles e suas respectivas colônias, num dado período da história da colonização; na Época Moderna, entre o 
Renascimento e a Revolução Francesa, parece-nos conveniente chamar essas relações [...] de Antigo Sistema Colonial da era mercantilista (NOVAIS, 1989, p. 57).

Partindo da ideia de que o mercantilismo era a política econômica típica das nações europeias do Antigo Regime, e que esta visava exclusivamente o lucro com o mínimo de custo e o máximo de exploração, observemos como Fernando Novais localizou o papel das colônias dentro dessa lógica:

\begin{abstract}
Neste contexto, vê-se bem o significado e a posição das colônias. Elas devem se constituir em retaguarda econômica da metrópole. Pois que a política mercantilista ia sendo praticada pelos vários estados modernos em desenfreada competição, necessário se fazia a reserva de certas áreas onde se pudesse por definição aplicar as normas de política econômica; as colônias garantiriam a autossuficiência metropolitana, meta fundamental da política mercantilista permitindo assim ao Estado colonizador vantajosamente competir com os demais concorrentes (NOVAIS, 1989, p. 20-21).
\end{abstract}

Desse modo, a história da colônia já estaria, em certa medida, pré-estabelecida por uma contingência que se realizaria fora de seus espaços.

Novais, assim como Caio Prado Jr. e Celso Furtado, entende que eram as necessidades da economia europeia ocidental que ditavam as "regras do jogo" das relações entre o centro e a periferia na economia-mundo do período moderno. Em outras palavras, eram as demandas das metrópoles que conformavam o papel das suas respectivas colônias, a saber: fornecer produtos agrícolas extremamente valiosos no mercado internacional; fornecer matérias-primas para a produção manufatureira e a posteriori maquino-fatureira; fornecer metais preciosos amoedáveis (demanda típica da política econômica mercantilista de Antigo Regime), além de assegurar a exclusividade do comércio para as suas respectivas metrópoles. Novais, assim, esclarece sobre o significado do sentido da colonização:

[...] ao se transitar do comércio para a colonização, passava-se da comercialização de bens produzidos por sociedades já estabelecidas para a produção de mercadorias e montagem de uma sociedade nova. Engajava-se, assim, a ocupação, povoamento e valorização de novas áreas, e sua integração nas linhas da economia européia. Aexploração ultrapassava dessa forma o âmbito da circulação de mercadorias, para promover a implantação de economias complementares extra-europeias [...] E não obstante tais diferenças fundamentais, e as dimensões novas que assumia a atividade colonizadora ao transcender a exploração do comércio ultramarino, a colonização guardou na sua essência o sentido de empreendimento comercial donde proveio; a não existência de produtos comercializáveis levou à sua produção, e disso resultou a ação colonizadora. Assim se ajustavam as novas áreas aos quadros das necessidades de crescimento da economia européia. A colonização moderna, portanto [...] tem uma natureza essencialmente comercial: produzir para o mercado externo, fornecer produtos tropicais e 
metais nobres à economia europeia, eis, no fundo, o sentido da colonização (NOVAIS, 1989, p. 68).

Por fim, concluindo a síntese do pensamento novasiano, é relevante mencionar a crise do Antigo Sistema Colonial que deve ser investigada dentro do próprio sistema em suas contradições internas. Enquanto o sistema colonial atendia as demandas da acumulação prévia de capitais, não havia contradição, pois as colônias de exploração ${ }^{2}$, funcionando como economias complementares das nações europeias, ao fornecer-lhes produtos valiosos altamente demandados e prover-lhes de matérias-primas necessárias à produção artesanal e ou manufatureira, garantia-lhes a autonomia e a competitividade no mercado internacional. Entretanto, esse processo, ao acelerar a acumulação primitiva de capitais por meio da já mencionada transferência de renda das colônias para as metrópoles, criou as bases para o surto maquinofatureiro que, por sua vez, necessitava da expansão da demanda nas áreas coloniais, o que certamente era incompatível com as características básicas das colônias inseridas no Sistema Colonial das sociedades do Antigo Regime. Eis o que Novais chamou de "núcleo dinâmico do sistema", ao funcionar plenamente, cria, em paralelo, as condições de sua crise e superação. Vejamos a seguir uma citação que ilustra mais amplamente essa visão:

O universo das relações mercantis é função dos senhores e, digamos, agregados. A massa de produtores diretos (escravos) vive fora das relações mercantis, e isso trava a constituição de um mercado interno. No conjunto, tal configuração do mundo colonial responde ao funcionamento do sistema, enquanto as economias centrais se desenvolvem apenas no nível da acumulação primitiva de capitais, e a produção se expande no nível artesanal, ou mesmo manufatureiro. Quando, porém essa etapa é ultrapassada, e a mecanização da produção com a Revolução Industrial, potenciando a produtividade de uma forma rápida e intensa, leva a um crescimento da produção capitalista num volume e ritmo que passam a exigir no ultramar mais amplas faixas de consumo, consumo não só de camadas superiores da sociedade, mas agora da sociedade como um todo, o que se torna imprescindível é a generalização das relações mercantis. Então o sistema se compromete, e entra em crise (NOVAIS, 1989, p. 112, grifo do autor).

O fato de a crise do Sistema Colonial ocorrer em meio a um momento de prosperidade econômica para a Metrópole lusitana, não configurou, segundo Novais, uma contradição, haja vista que as relações entre Portugal e Brasil eram apenas parte desta estrutura mais ampla denominada Sistema Colonial, no qual Portugal estava longe

\footnotetext{
${ }^{2}$ Conceito básico e necessário para distinguir as colônias que faziam parte do Antigo Sistema Colonial, a exemplo das zonas tropicais e as que não fizeram parte, pelo menos em um primeiro momento, como as zonas temperadas por não satisfazer, de imediato e a contento, as demandas do mercado europeu, ao se constituírem enquanto colônias de povoamento.
} 
de ocupar, àquela altura, posição de protagonismo. Aliás, o próprio Sistema Colonial, denominado de estrutura, se constitui enquanto tal apenas do ponto de vista econômico. Em outras palavras, o Antigo Sistema Colonial é apenas a face econômica das sociedade do Antigo Regime, essa, sim, a verdadeira estrutura em crise.

No aspecto econômico, Novais apresenta todo o esforço inspirado em um despotismo esclarecido português a partir do consulado pombalino para defender o território, fortalecer o exclusivo, minimizar o contrabando, essas e outras medidas com o intuito de promover o superávit da balança comercial portuguesa, o que ocorreu em alguma medida durante um determinado momento (1796-1801), mas também e primordialmente, fomentar o desenvolvimento industrial português bastante débil. $\mathrm{O}$ arranque das fábricas portuguesas até ocorreu, todavia era imprescindível, para que o processo fosse concluído, a manutenção das relações com a sua principal colônia nos moldes do exclusivo-metropolitano. Novais conclui que tal iniciativa foi implementada tardiamente e o pequeno país não suportaria a pressão do desenvolvimento industrial inglês. Nas palavras do próprio autor, "o desenvolvimento do industrialismo na Inglaterra levava a potência hegemônica a focejar, seja pelo contrabando, pela ameaça ou pela diplomacia a abertura dos mercados coloniais dos países ibéricos" (NOVAIS, 1989, p. 197). Em outra passagem, diz Novais: “O contrabando arromba as portas em 1808” (NOVAIS, 1989, p. 196). Vejamos como em ambas as citações o centro dinâmico das relações metrópole-colônia, concentra-se, desta vez, no exterior e não em Portugal - por ocupar posição periférica dentro do sistema -, mas na Inglaterra pelo motivo inverso. Essa é a visão teórica que conduz a linha mestra de análise da obra clássica de Fernando Novais.

Esse autor fecha o bloco daqueles que se convencionou chamar na historiografia de "Escola do Sentido da Colonização". Essa linha interpretativa foi amplamente aceita e propagada durante boa parte do século XX, entretanto, ao mesmo tempo em que ampliava o "leque" de pesquisadores que a seguia, ensejou as primeiras críticas. A mais comum delas era a de que tais historiadores enfatizaram excessivamente a capacidade de influência do mercado externo nas principais características que regiam a economia colonial. De acordo com a vertente alternativa de interpretação, a relação entre Portugal e Brasil resultava de uma ligação complexa, suficiente para promover a formação de uma estrutura própria na colônia e que não se constituía apenas como reflexos das estruturas europeias. Tal relação (metrópole/colônia), portanto, promoveu uma dinâmica interna própria para a colônia, o que exigiria, segundo estes autores, uma análise detida 
das suas características próprias. Jacob Gorender, um dos representantes desta inovação interpretativa, assim apresentou a nova estratégia metodológica que se impunha:

A desobstrução metodológica impõe a inversão radical do enfoque: as relações de produção da economia colonial precisam ser estudadas de dentro para fora, ao contrário do que tem sido feito, isto é, de fora para dentro (tanto a partir da família patriarcal ou do regime jurídico da terra, quanto a partir do mercado ou do sistema colonial). A inversão do enfoque é que permitirá correlacionar as relações de produção às forças produtivas em presença e elaborar a categoria de modo de produção escravista colonial na sua determinação específica (GORENDER, 1992, p.7).

\section{O Modo de Produção Escravista Colonial}

A especificidade da colônia seria o ponto nevrálgico do novo modelo explicativo, que irá propor a existência de um modo de produção próprio para a colônia, o escravismo. Nessa linha interpretativa destacaram-se Jacob Gorender e Ciro Flamarion Santana Cardoso. Embora haja diferenças substanciais entre os autores, sobretudo no que se refere ao escravismo ${ }^{3}$, ambos convergem em relação às críticas acerca das principais características de interpretação dos autores da "Escola do Sentido da Colonização".

Jacob Gorender, motivado em compreender a expropriação da riqueza, a desigualdade social e o subdesenvolvimento do Brasil, escreve, em 1980, o livro "Escravismo Colonial”. Se em Caio Prado Jr., Celso Furtado e Fernando Novais, o núcleo dinâmico da análise é o capital mercantil, no qual a obtenção do excedente estaria na relação sistêmica entre Portugal e Brasil, para Gorender, essa apropriação ocorreria internamente pela exploração do trabalho, na relação entre senhores e escravizados.

$\mathrm{Na}$ busca por assegurar consistência para sua hipótese, o autor desenvolve a ideia de que na colônia houve um modo de produção sui generis, o "modo de produção escravista colonial”. A singularidade de tal modo de produção exigiu a construção de um modelo explicativo que envolvesse, da mesma maneira, leis monomodais. ${ }^{4}$ Foram

\footnotetext{
${ }^{3}$ Os autores se distanciam quando se trata do escravismo. Diferentemente de Gorender, Ciro Cardoso demonstra, através de suas pesquisas empíricas com fontes primárias à medida que o escravizado tomava consciência da existência da brecha camponesa, melhor ele a explorava, possibilitando-o maior grau de autonomia dentro do sistema escravista. Já nos trabalhos de Gorender, o escravizado sempre ocupou uma posição fixa ou linear, com pouco espaço para autonomia e negociação.

${ }^{4}$ Conceito dado por Gorender no esforço de elaborar um modelo explicativo sobre a economia colonial. Essa economia por ser singular, segundo o autor, deveria ser compreendida por meio de suas características próprias, a partir de leis monomodais, ou seja, leis de modelo único/exclusivas.
} 
cinco no total, as quais retomaremos um pouco mais a frente. Interessa-nos, agora, chamar a atenção para as principais críticas do autor em relação à Escola do Sentido da Colonização. A primeira consiste na ênfase dada à dinâmica do mercado externo para a compreensão da economia colonial. A segunda gira em torno do circulacionismo. ${ }^{5}$ Para ele, toda obra que se expresse pelo marxismo deveria buscar compreender a sociedade examinada pela esfera da produção e não da circulação. Segundo Gorender, os autores que privilegiaram o mercado externo acabaram por deixar a esfera da circulação se sobrepor a da produção:

Focalizando agora a linha de interpretação, que se concentrou no mercado e dele fez a chave explicativa da economia colonial, constatamos um resultado invariável desse procedimento metodológico: a sobreposição da esfera da circulação às relações de produção (GORENDER, 1992, p. 6).

Retomando a primeira crítica, Gorender defende que as relações entre Portugal e Brasil promoveram o surgimento de uma economia e sociedade ímpares, que deveria ser analisada em si e não em relação à outra economia/sociedade. $\mathrm{O}$ autor propõe a existência de um modo de produção específico para a economia colonial baseado no escravismo. Para defender esta tese, apresentará as leis que regem o sistema, da mesma maneira também exclusivas (monomodais). Seriam elas:

lei da renda monetária, lei da inversão inicial da aquisição do escravizado, leis da rigidez da mão de obra escravizada, lei da correlação entre economia mercantil e economia natural na plantagem escravista e lei da população escravizada (GORENDER, 1992, p. 164).

Identificamos certa vulnerabilidade na teoria estabelecida por Gorender, na medida em que a maioria dessas "leis" se mostraram controversas, pois tendem a contradizer o pensamento do autor. De acordo com Gorender, a economia colonial deveria ser compreendida a partir do estudo dos seus mecanismos próprios de funcionamento e não da premissa da condição de extrema dependência da economia colonial ao processo de formação do capitalismo europeu.

Vejamos dois exemplos da contradição de Gorender em relação à sua ideia central. Selecionamos duas leis para ilustrá-la. A lei da renda monetária e a lei da

\footnotetext{
${ }^{5}$ Expressão utilizada por historiadores econômicos que buscam analisar uma determinada sociedade a partir da esfera da circulação e não da produção de mercadorias. Muitos historiadores econômicos do período moderno, inclusive marxistas, buscam compreender a acumulação primitiva de capitais por intermédio de uma das características básicas do capital mercantil, a circulação. Não obstante, para Gorender, todo historiador que almeja examinar uma dada sociedade, tendo como referência teórica as obras de Marx, deve buscar a acumulação de capitais na esfera da produção e não da circulação.
} 
população escrava, respectivamente. Na lei da renda monetária, o autor trata, basicamente, da transferência do excedente econômico produzido pelo escravizado e apropriado pelo Senhor. Nesta passagem do livro, o autor compara a escravidão antiga com sua economia natural e a escravidão moderna, essa última, ao produzir fluxo monetário no processo de exploração dos cativos pelos senhores. Ao considerar os senhores de terras e escravizados como aqueles que se apropriam do excedente econômico em forma de renda monetária, o autor vincula o modo de produção escravista colonial ao setor exportador, ou seja, dependente dele.

Na lei da população escrava, Gorender ressalta as péssimas condições de vida do escravizado na colônia, que, por viver em condições insalubres, teria a sua reprodução natural afetada. Ora, se as condições de trabalho contribuíam para a diminuição absoluta da população escravizada, como pôde o sistema ou, nas palavras do autor, o escravismo, sobreviver por três séculos? Obviamente, a resposta situa-se no tráfico transatlântico de escravizados, ou seja, no mercado externo. Mais uma vez, o autor acaba vinculando o funcionamento da economia colonial ou o modo de produção escravista ao mercado externo. Consequentemente, por não realizar o que ele mesmo propôs, ou seja, analisar a economia colonial de forma sui generis, manteve-se refém de sua maior crítica, não conseguindo observar os mecanismos próprios de funcionamento da economia colonial desvinculados da economia europeia.

Ao apresentar as leis específicas do modo de produção escravista colonial, Gorender insistiu na justificativa da centralidade do escravismo. Em determinado trecho, ele afirma que "mais do que viável, o trabalho escravo era vantajoso na produção em grande escala de gêneros tropicais de exportação" (GORENDER, 1992, p. 206) para, em seguida, comparar o escravismo à terra no feudalismo e ao capital no capitalismo:

\footnotetext{
O escravo não representou fato contingente, expediente ditado pelo arbítrio ou surgido de circunstâncias ocasionais. À mesma maneira que a propriedade da terra é o fator socialmente decisivo de domínio da produção no feudalismo e a propriedade do capital, no capitalismo, os contemporâneos do escravismo tiveram a clara noção de que a propriedade de escravos constituía o fator decisivo, o fator fundamental de domínio da produção na economia existente no Brasil (GORENDER, 1992, p. 206).
}

Percebe-se em tal assertiva que o enquadramento do uso de mão de obra escrava no período colonial brasileiro foi uma derivação que se enquadrou nas leis características do modo de produção escravista colonial, portanto, algo já previamente 
estabelecido dentro do quadro teórico do modo de produção. Outro elemento resultante desse processo refere-se ao impacto social em que a condição de fator decisivo de domínio da produção daria ao grande proprietário de escravizados, não só a medida de sua força econômica, como também o posicionava na estrutura de classes colonial.

Ao fim, quando pensamos na aplicação de uma análise sistêmica mais ampliada para entender as relações entre colônia e metrópole, no interior do Antigo Regime europeu, somos motivados pelo grau de diversificação que uma relação tão complexa pode admitir. No caso de Gorender, diríamos que esse superlativou a dinâmica interna ao buscar estabelecer um modo de produção próprio para a fase colonial da história do Brasil, tangenciando o capital comercial do centro da interpretação da relação metrópole-colônia, substituindo-o pela categoria "escravismo".

Outro que apresentou pensamento interpretativo em alternativa ao "Sentido da Colonização" foi Ciro Flamarion Santana Cardoso. Um dos grandes historiadores brasileiros da segunda metade do século XX se constituiu como "peça-chave" no debate acerca do funcionamento da economia colonial. ${ }^{6}$ Buscou relativizar o modelo explicativo sistêmico e, a partir da utilização do conceito "modo de produção", , buscou as especificidades da colônia brasílica por meio de estudos sobre as suas estruturas internas, seus movimentos próprios para além da ligação com o mercado externo e com a economia de plantation. Entendemos que a grande contribuição de Ciro Cardoso para o debate acerca da economia colonial gira em torno dos estudos sobre a brecha camponesa $^{8}$.

Segundo o autor, havia a possibilidade no interior do sistema escravista para o desenvolvimento de atividades agrícolas autônomas por parte do escravizado fora da economia de plantation. O escravizado gozava, periodicamente, de tempo livre e de acesso estável à terra, além de certo grau de independência para a administração de suas

\footnotetext{
${ }^{6}$ Eis algumas de suas obras que foram importantes neste processo: CARDOSO, C.F.S. Escravo Ou Camponês? O Proto-Campesinato Negro Nas Américas. São Paulo: Brasiliense, 1987; O trabalho na América Latina Colonial. São Paulo: Ática, 1985; A Afro-América: a escravidão no Novo Mundo. Rio de Janeiro: Graal, 1981; Agricultura, Escravidão e Capitalismo. Petrópolis: Vozes, 1979.

${ }^{7}$ Pelo menos em uma primeira fase de sua trajetória acadêmica, pois com o maturar de suas ideias passou a adotar, paulatinamente, o conceito de formação econômico-social, presente nos trabalhos do antropólogo francês Maurice Godelier. Cf GODELIER, Maurice. Horizontes da Antropologia. Lisboa: Edições 70, s/d.e SERENI, Emilio. La Categoria de"Formación econômica y social. In: LUPORINI, Cesare\& SERENI. El concepto de fomación econômico-social. $3^{\mathrm{a}}$ Ed. México, Cuadernos do Pasado y Presente (39), 1978. E. Sereni, cf. La Categoria de "Formación econômica y social". México: Roca, 1973. ${ }^{8}$ Ciro Cardoso importou a expressão brecha camponesa do historiador lituano Tadeusz Lepkowski que introduziu esse conceito ao analisar as atividades agrícolas de subsistência desenvolvidas no interior das plantations haitianas.
} 
atividades agrícolas. Apesar da "brecha" se referir fundamentalmente à economia de subsistência, a autonomia que era conferida ao escravizado por vezes permitia que sua produção fosse vinculada ao mercado.

Para Cardoso, houve, na colônia, duas modalidades de brecha camponesa: uma que funcionava como mero complemento da alimentação escrava e que, ao disponibilizar pedaços de terra menor e menos tempo livre para o cultivo da lavoura de subsistência, não se constituiu como principal fonte de alimentos para os cativos. A outra, ao ofertar mais tempo e mais terras aráveis aos escravizados, muitas vezes configurou-se como única fonte de alimentos, desonerando o senhor desses custos de manutenção. Para o autor, não houve um padrão, ou seja, a predominância de uma modalidade sobre a outra, pois elas coexistiram:

[...] a brecha camponesa podia ter uma função meramente complementar à distribuição de rações aos escravos, a intervalos regulares, pelos senhores ou seus representantes: neste caso, as parcelas entregues aos cativos limitavamse a quintais próximos às suas cabanas, e o tempo livre de que dispunham era menor[...] ]ou, então, podia colocar-se como alternativa às distribuições de rações, as quais[...] os escravos recebiam, neste caso, lotes situados fora do núcleo central da plantation, além dos quintais adjacentes às suas moradias, e dispunham de mais tempo para cultivar suas parcelas (CARDOSO, 1987, p. $88)$.

Ciro Flamarion Cardoso utilizou o conceito "brecha camponesa" para estudar essencialmente o protocampesinato escravo, não obstante, o referido conceito pode ser ampliado, a exemplo do que fez o antropólogo estadunidense, Sidney Mintz, incluindo, em sua análise para as Antilhas, os camponeses livres proprietários e não proprietários de terra ${ }^{9}$ (MINTZ, 1974, p. 146-156). O alargamento do referido conceito contribuiu para o desenvolvimento de pesquisas acerca do homem pobre livre e das camadas intermediárias da sociedade colonial, ${ }^{10}$ deixando para trás uma visão simplificada da história do Brasil em torno do binômio senhor/escravo.

O estabelecimento do conceito "brecha camponesa", ao passo que refutou as ideias da "Escola Sociológica Paulista" 11 acerca do papel do escravizado dentro do

\footnotetext{
${ }^{9}$ MINTZ, S. W. Caribbean Transformations. Chicago: Aldine, 1974.p.146-56; Slavery, Colonialismand Racism. New York: W.W. Norton, 1996. Sweetnessand Power: The Place of Sugar in ModernHistory. New York: Viking-Penguin, 1985; O poder amargo do Açúcar. Recife: Editoria Universitária, 2003.

${ }^{10}$ SOUZA, L. M. Desclassificados do ouro: a pobreza mineira no século XVIII. 1. ed. Rio de Janeiro: Graal, 1983; MATTOS, Hebe. Ao Sul da História: lavradores pobres na crise do trabalho escravo. São Paulo: Brasiliense, 1987; FERLINI, Vera Lúcia Amaral. Pobres do açúcar: Estrutura Produtiva e Relações de Poder no Nordeste Colonial. In: História Econômica do período colonial. Tamás Szmerecsániy. (Org.). 2 ed. revista. São Paulo: Hucitec/ABPHE/Edusp/Imprensa Oficial, 2002.

${ }^{11}$ Preocupados na elaboração de estudos sociológicos de análise macroestrutural, como por exemplo, o desenvolvimento do capitalismo e os efeitos de sua penetração no Brasil, esta corrente que surge no final
} 
sistema escravista, colaborou com o surgimento de excelentes pesquisas no campo d História Social e Econômica do Brasil. No que tange à História Social, os trabalhos se concentraram no estudo endógeno da escravidão. Em verdade, os estudos relacionados à história da escravidão, no Brasil, foram os que mais cresceram nos últimos trinta anos. São inúmeros os trabalhos monográficos de cunho regional que irrigaram a produção historiográfica brasileira nessa temática. ${ }^{12}$

No plano econômico, buscou-se estudar o interior da estrutura, a saber: a economia de subsistência, o mercado interno e o grau de autonomia dessas atividades em relação à economia de exportação. Nessa abordagem da história, merecem destaque os historiadores cariocas João Luiz Ribeiro Fragoso e Manolo Garcia Florentino. Esses autores formarão a última seção deste ensaio. Antes, devemos concluir a discussão em torno daqueles que propuseram um modo de produção específico para a economia colonial.

Entendemos ser equivocado a tentativa de adaptar o conceito marxista "modos de produção" à colônia brasílica. Independentemente da abordagem que seja adotada, seja ela privilegiando a acumulação endógena ou exógena, seja analisando a partir da esfera da produção ou da circulação, o que é mais importante, nesse caso, é perceber que a economia e a sociedade colonial se desenvolveram em um período híbrido, sem características próprias bem definidas, portanto, em um período de transição. E, como em toda transição, haverá rupturas e permanências.

da década de 1950, acabou por não enfatizar o papel do escravizado dentro do sistema. Em outras palavras, por se dedicar a estudos sistêmicos da sociedade escravista no Brasil, a "Escola Sociológica Paulista" privilegiou o exame das relações escravistas de produção em detrimento de uma análise mais aprofundada dos agentes históricos, renegando, por exemplo, o papel do escravizado como sujeito ativo do processo histórico. O escravizado aparece apenas como uma mercadoria valiosa e como mão de obra principal. A sua participação nesses trabalhos se resume, portanto, ao seu valor de uso e de troca. Dentre os vários estudiosos dessa corrente de pensamento, podemos citar Florestan Fernandes, Fernando Henrique Cardoso, Otávio Ianni, Emília Viotti da Costa, entre outros.

${ }^{12}$ QUEIRÓS, Suely Robles Reis de. Escravidão negra em São Paulo: um estudo das tensões provocadas pelo escravismo no século XIX. Rio de Janeiro: José Olympio, 1977; GAMA, Lana Lage. Rebeldia negra e abolicionismo. Rio de Janeiro: Achiame, 1980; REIS, João José. Rebelião escrava no Brasil. A história do levante dos malês (1835).1ed: São Paulo: Brasiliense, 1986; MACHADO, Maria Helena Pereira Toledo. Crime e escravidão. Trabalho, luta e resistência nas lavouras paulistas 1830-1888. 1 ed. São Paulo: Brasiliense, 1987; LARA, Silvia Hunold. Campos de violência: Escravos e Senhores na Capitania do Rio de Janeiro, 1750-1808. Rio de Janeiro: Paz e Terra, 1988; ALGRANTI, Leila Mezan. O Feitor Ausente. (estudo sobre a escravidão urbana no Rio de Janeiro, 1808-1821. 1 ed. Petrópolis: Vozes, 1988; CHALHOUB, Sidney. Visões da Liberdade: uma história das últimas décadas da escravidão na Corte São Paulo, Companhia das Letras, 1990; SLENES, Robert Wayne Andrew . Na Senzala, Uma Flor: Esperanças e Recordações Na Formação da Família Escrava (Brasil Sudeste, Século XIX). Rio de Janeiro: Nova Fronteira, 1999, dentre outros. 
Em consonância com o que defende João Manuel Cardoso de Mello (1982) ${ }^{13} \mathrm{e}$ José Jobson de Andrade Arruda (1980) ${ }^{14}$, compreendemos ser a economia colonial parte integrante de algo mais amplo, a acumulação primitiva de capitais, etapa necessária e "mola propulsora" do surgimento do capitalismo industrial na Europa Ocidental, e não como um modo de produção específico:

[...] impossível conceber um Modo de Produção Colonial [...] Que modo de produção é este que não parece reter em si qualquer especificidade quanto ao tipo e ao nível das forças produtivas e correspondentes relações sociais de produção? Que modo de produção é este que não se reproduz e cuja dinâmica depende [...] de contradições que lhe são próprias?

Mas, por outro lado, pergunto: é possível conceber o movimento, isto é, a transição do feudalismo para o capitalismo, abstraindo o papel desempenhado pelas economias coloniais? Não: tanto a acumulação de capital e sua concentração nas mãos da burguesia comercial metropolitana quanto a criação de mercados coloniais foram fatores essenciais [...] à constituição do capitalismo.

O que há portanto, é uma única totalidade [...] em que o "sentido" e os rumos são determinados pelas contradições que animam as economias metropolitanas. Se a economia colonial e economia metropolitana são faces da mesma moeda, empresa colonial e manufatura (tomada como a estrutura produtiva apanha o "sentido" da marcha rumo ao "capitalismo industrial") também o são (MELLO, 1982, p. 42-43).

Tanto o período moderno europeu quanto o período colonial no Brasil são diferentes "faces da mesma moeda", ou seja, a fase de acumulação primitiva de capitais, em termos mais gerais, a longa fase de transição do Feudalismo para o Capitalismo, não se constitui em si mesma um modo de produção sui generis. O próprio Marx nos ensina isso em diversas passagens de sua obra. Vejamos algumas: “A estrutura econômica da sociedade capitalista nasceu da estrutura econômica da sociedade feudal. A decomposição desta liberou elementos para a formação daquela” (MARX, 1996, p. 830). Já na "Contribuição a crítica da economia política", Marx afirma: "Em grandes traços, podem ser os modos de produção asiático, antigo, feudal e burguês moderno designados como outras tantas épocas progressivas da formação da sociedade econômica" (MARX, 2008, p. 48).

\section{A chamada "Escola do Rio"}

\footnotetext{
${ }^{13}$ MELLO, João Manuel Cardoso de. O Capitalismo Tardio. São Paulo: Brasiliense, 1982.

${ }^{14}$ ARRUDA, José Jobson de Andrade. O Brasil no comércio colonial. São Paulo: Ática, 1980.
} 
Influenciados, dentre outros autores, pelos estudos de Ciro Flamarion Cardoso ${ }^{15}$ e Maria Yedda Leite Linhares ${ }^{16}$, João Fragoso e Manolo Florentino no livro o “Arcaísmo como Projeto", propuseram um modelo explicativo divergente dos modelos pré-existentes sobre a economia colonial. O referido livro trata, em grande medida, da síntese das teses de doutoramento de ambos os autores.

Em sua tese, João Fragoso buscou compreender as formas de acumulação das elites cariocas coloniais, enquanto Manolo Florentino analisou o tráfico de escravizados da costa africana para o porto do Rio de Janeiro. ${ }^{17}$ Apesar das diferenças, a confluência dos dois trabalhos foi possível, por se tratar de produções com arcabouço teóricometodológico e escopo documental semelhantes.

Desde a publicação anterior, resultante imediata de sua tese ${ }^{18}$, João Fragoso já apresentara o modelo teórico que o acompanharia até a primeira edição de o “Arcaísmo". A partir de conceitos, tais como,: "acumulação endógena", "mercado interno" e "capital residente", o autor constata que havia a "possibilidade de retenção de parte do excedente da agroexportação e das produções ligadas ao mercado interno" (FRAGOSO, 1992, p. 28) e de "uma relativa autonomia do processo de reprodução da economia considerada frente às flutuações do mercado internacional" (FRAGOSO,1992, p. 28). Portanto, para além da constatação da existência de um considerado mercado interno, o autor propõe que esse era agente promotor de uma dinâmica própria para a economia colonial, independentemente, das flutuações do mercado internacional.

Para chegar a tal conclusão, o autor busca defrontar a economia colonial carioca com a economia internacional entre 1790 a 1850. Como método, vale-se da teoria do

\footnotetext{
${ }^{15}$ As obras de Ciro Cardoso que se relacionam com tal influência já foram supracitadas.

16 A principal influência de Maria Yedda Leite Linhares sobre Fragoso e Florentino concentra-se, principalmente, nos estudos sobre a história da agricultura e do abastecimento no Brasil, seja os trabalhos desenvolvidos individualmente, seja em parceria com Francisco Carlos Teixeira da Silva. Cf: LINHARES, Maria Yedda Leite. História do Abastecimento - uma problemática em questão, 1530-1918. Brasília: Biblioteca Nacional de Agricultura, 1979; LINHARES, Maria Yedda Leite e SILVA, Francisco Carlos Teixeira da. História da Agricultura Brasileira - Combates e Controvérsias. São Paulo: Editora Brasiliense, 1981; LINHARES, Maria Yedda Leite e SILVA, Francisco Carlos Teixeira da. História Política do Abastecimento (1918-1974). Brasília: Biblioteca Nacional de Agricultura, 1979.

17 A partir dos anos de 1990, há uma preocupação, cada vez maior, dos historiadores econômicos coloniais e do século XIX em estudar o interior da estrutura. Cf: FARIA, S. S. C.A Colônia em Movimento, Fortuna e Família no Cotidiano Colonial. 1. ed. Rio de Janeiro: Nova Fronteira, 1998; BARICKMAM, B. J. Um Contraponto baiano: açúcar, fumo, mandioca e escravidão no Recôncavo, 1789-1860. Rio de Janeiro. Ed. Civilização Brasileira, 2003.

${ }^{18}$ FRAGOSO, J. L. R.. Homens de Grossa Aventura: Acumulação e Hierarquia Na Praça Mercantil do Rio de Janeiro (1790 -1830). 1. ed. Rio de Janeiro: Arquivo Nacional, 1992.
} 
economista russo Nicolai Kondratieff, ${ }^{19}$ dividindo o período supracitado em duas fases: entre 1792 e 1815 (fase A) de crescimento e entre 1816 e 1850, (fase B) de depressão, conforme se pode verificar na citação a seguir:

\begin{abstract}
A primeira fase, em meio a guerras e bloqueios, foi marcada, tanto na Inglaterra como na França, pela concentração urbana, por mudanças nos padrões de vida, nos da produção industrial e agrícola, e pela ampliação do comércio. Para o Brasil, essa fase representou uma melhoria da situação internacional de seus produtos agrícolas, especialmente o açúcar e algodão traduzindo-se em uma tendência de alta de preços. Desse modo, pode-se dizer que, na fase A, o Brasil acompanha o ciclo internacional. Entretanto, o mesmo não pode ser dito para o seguinte $(1815-1850)$, que, em termos de conjuntura internacional (leia-se Europa), se traduziria na fase B do ciclo (FRAGOSO, 1992, p.19-20).
\end{abstract}

Portanto, no primeiro momento, a conjuntura externa de guerras beneficiou a economia colonial, entretanto, essa relação inversamente proporcional entre a colônia e o mercado externo, segundo Fragoso, não ocorreu em uma segunda fase. Ou seja, na fase B, apesar de se tratar de um momento de relativo retorno da estabilidade política das nações europeias ocidentais com a retomada do crescimento produtivo em setores que concorriam com os produtos coloniais, a economia colonial não foi caracterizada por um quadro recessivo. Para exemplificar essa visão, o autor apresenta dados do mercado - intercapitanias:

Passando para o período correspondente à fase $\mathrm{B}$ do Kondratieff, continuamos a encontrar exemplos de alta para as produções voltadas para $\mathrm{o}$ mercado interno colonial. Entre 1815 e 1822, as receitas do charque gaúcho que entra no porto carioca aumentam em 69,8\%. Já as saídas de reses, toucinho e carne salgada de Minas Gerais, pelo Registro do Presídio de Rio Preto, se ampliam em mais de 170\%, entre 1818 e 1828 (FRAGOSO, 1992, p. 23).

Fragoso ainda faz uma crítica aos autores clássicos da economia colonial que, segundo ele, negligenciaram as flutuações próprias da economia colonial, como se pode observar na passagem a seguir:

Havia, portanto, a mais perfeita congruência entre o panorama externo e algumas características da economia fluminense. Se remetermos esse quadro geral à apreciação dos clássicos modelos de explicação da economia colonial, deveremos esperar a mais completa déblâcle da estrutura produtiva fluminense, pois, de acordo com tais modelos, esta última não possuiria flutuações próprias (FLORENTINO; FRAGOSO, 2001, p. 93).

\footnotetext{
${ }^{19}$ Este autor buscou estudar, por meio de métodos estatísticos, os movimentos cíclicos da economia.
} 
Mas o que explicaria a acumulação endógena e a dinâmica própria e independente da economia colonial frente às flutuações do mercado externo? Partindo da apresentação de dados que demonstra um Portugal atrasado com a manutenção de suas estruturas agrárias tradicionais (FLORENTINO; FRAGOSO, 2001, p. 41-42) e inspirados no plano teórico-metodológico pela "Revolução historiográfica", a partir da década de $1970^{20}$, nomeadamente pela micro história italiana com o seu profícuo diálogo interdisciplinar com a Antropologia, Fragoso e Florentino buscam entender tais movimentos em elementos exógenos à economia. Tais explicações residiriam nos aspectos sociais e culturais de Portugal do período moderno. Segundo os autores, em Portugal:

[...] prevaleciam valores não-capitalistas, para os quais ascender na hierarquia social[...]implicava tornar-se membro da aristocracia. Daí a grande propensão dos meios mercantis à aristocratização, e a canalização e esterilização de vultosos recursos adquiridos na esfera mercantil para atividade de cunho senhorial [...] o "atraso" português em pleno século XVII, não se constituísse em mero anacronismo, fruto de uma putativa incapacidade de acompanhar o destino manifesto capitalista europeu; ao contrário, o arcaísmo era...um verdadeiro projeto social, cuja viabilização dependia [...] das rendas coloniais... O capital mercantil português deve ser tomado como um dos exemplos mais radicais do modelo de circulação [...] Com uma diferença fundamental em relação, por exemplo, à estrutura do capital mercantil inglês, holandês e [...] francês da Época Moderna: a atividade comercial lusitana tinha por fim último a permanência de uma sociedade arcaica, não chegando a assumir os contornos revolucionários que desempenhava em outros países. (FLORENTINO; FRAGOSO, 2001, p. 52-53).

Portanto, como se pode observar a partir da citação, o "atraso" português em relação às principais economias europeias, não significou, segundo os autores, em uma dificuldade ou incompetência lusitana de modernizar a nação ou desenvolvê-la em termos capitalistas, pelo contrário, era resultado do ideal aristocrático que perpassou a sociedade portuguesa do período moderno, sendo o arcaísmo um verdadeiro projeto de nação. A manutenção desse projeto arcaico, entretanto, era extremamente dependente da economia colonial e essa dependência explica em grande medida, segundo Fragoso e Florentino, o certo grau de autonomia da economia colonial, como se pode verificar na citação abaixo:

O capital mercantil metropolitano voltava-se quase que integralmente para a apropriação do resultado final da atividade econômica colonial [...] Tal situação constitui, em si mesma, a primeira variável que ajudava a modelar a economia colonial. Em face de um projeto colonizador que prescindia de uma

\footnotetext{
${ }^{20}$ Refiro-me à história social inglesa, à história cultural francesa e à micro história italiana que a partir de novos objetos, perspectivas e abordagens, novas fontes ou a ressignificação de fontes já conhecidas pelo historiador que contribuíram significativamente para a produção historiográfica internacional.
} 
burguesia metropolitana forte, era fácil à economia colonial adquirir certa autonomia [...] Em outras palavras: a estrutura de produção colonial gerava seus mercados de homens e alimentos, o que, por sua vez, viabilizava a aparição de circuitos internos de acumulação para além das trocas com a Europa (FLORENTINO; FRAGOSO, 2001, p. 54).

Os trabalhos supracitados de João Fragoso, tanto o produzido individualmente quanto o produzido em parceria com Manolo Florentino, contribuíram, indubitavelmente, para o enriquecimento do debate em torno das teorias acerca do funcionamento da economia colonial. Ao possibilitar um novo olhar sobre a colônia, colaboraram com o surgimento de estudos de cunho monográfico sobre os circuitos mercantis no interior da colônia. ${ }^{21}$ Não obstante, a sua teoria de um mercado interno significativo com certo grau de autonomia em relação aos movimentos da economia internacional deve ser utilizada com cautela quando se tratar de estudos sobre os primórdios da colonização e/ou sobre regiões afastadas das grandes urbes coloniais.

Os resultados que possibilitou Fragoso utilizar conceitos como, "acumulações endógenas" e "capital residente", são decorrentes de um objeto de pesquisa que tem como circunscrição geográfica o Rio de Janeiro, entre finais do século XVIII e os quatro primeiros decênios da centúria seguinte. Estamos, portanto, diante de um estudo acerca da "Cabeça do Estado do Brasil", desde 1763, e "capital" do vasto império português a partir de 1808 com a transferência da Corte de Lisboa para o Rio de Janeiro. O lócus estudado por Fragoso, caracterizava privilegiada posição geográfica com vocação para grande entreposto comercial e mantenedor de um comércio ativo com o Rio do Prata desde o século XVI. Além disso, ainda seria beneficiado pelo abastecimento e pelas trocas mercantis com as Minas Gerais, a partir de 1690, com a descoberta das jazidas de ouro, além de cada vez mais integrada ao comércio transoceânico em decorrência da crescente produção açucareira. ${ }^{22}$ Diante dessa realidade, não seria difícil encontrar uma

\footnotetext{
${ }^{21}$ SAMPAIO, Antonio Carlos Jucá de. Na encruzilhada do império: hierarquias sociais e conjunturas econômicas no Rio de Janeiro (c.1650 - c.1750). 1. ed. Rio de Janeiro: Arquivo Nacional, 2003;GIL, T. L.. Os Infiéis transgressores: elites e contrabandistas nas fronteiras do Rio Grande e do Rio Pardo (17601810). Rio de Janeiro: Arquivo Nacional, 2007;KELMER MATHIAS, C. L. As múltiplas faces da escravidão: o espaço econômico do ouro e sua elite pluriocupacional na formação da sociedade mineira setecentista, c. 1711 - c. 1756. 1. ed. Rio de Janeiro: Mauad X: FAPERJ, 2012; PESAVENTO, F. Um pouco antes da Corte: a economia do Rio de Janeiro na segunda metade do setecentos. 1. ed. Jundiaí: Paco Editorial, 2013; Alexandre Vieira Ribeiro. A Cidade de Salvador: estrutura econômica, comércio de escravos, grupo mercantil (c.1750-c.1800). 2009. Tese (Doutorado em História Social) - Universidade Federal do Rio de Janeiro.

${ }^{22}$ Segundo o próprio João Fragoso, em 1585, havia apenas três engenhos na Capitania fluminense. Em 1612, esse número havia saltado para quatorze, em 1680, já ultrapassava cento e trinta engenhos. Em 1800, apenas a região de Campos dos Goitacazes possuía trezentos e vinte e quatro engenhos. Para mais informações. Cf., FLORENTINO, Manolo e FRAGOSO, João Luís Ribeiro, op. cit, 2001, p. 63-75.
} 
economia dinâmica e complexa com certo grau de autonomia em relação aos grandes centros do capital mercantil europeu. Por outro lado, é importante ponderarmos que a estratégia metodológica utilizada por Fragoso, ao restringir sua investigação ao Rio de Janeiro em uma limitada cronologia histórica, mostra-se deficitária em termos de conclusões para uma abrangência temporal maior. Nesse caso, o próprio Fragoso já se deu conta dessa limitação quando fez a seguinte ressalva ao se referir a trabalhos enquadrados em análise temporal mais restrita:

\begin{abstract}
Grande parte das investigações há pouco citadas teve como objeto o Rio de Janeiro e São Paulo de fins do século XVIII e, principalmente, o século XIX. Apesar desse recorte temporal, aqueles trabalhos, inclusive o meu, possuíam o velho vício e a arrogância da tradição ensaísta brasileira, qual seja: a tentação de, a partir de investigações de apenas um curto período e uma região, explicar, por meio de esquemas lógicos, o conjunto temporal da sociedade escravista da América lusa, inclusive seu vasto período colonial (de 1500 a 1822) (FRAGOSO, 2012, p. 111).
\end{abstract}

Isso posto, gostaríamos de salientar que a discussão em torno da importância do mercado interno não é necessariamente uma novidade dos trabalhos dos anos de 1990. Deve-se fazer justiça às preocupações do historiador paulista, José Roberto do Amaral Lapa, que se debruça sobre essa temática desde a década de $1970 .{ }^{23}$ Não obstante, o próprio autor afirma, em trabalho posterior resultante de sua comunicação apresentada no primeiro Congresso Brasileiro de História Econômica, realizado em 1993, que: “O comércio interno... É um tema... Relativamente novo no conhecimento histórico brasileiro, residindo muitas vezes o seu estudo muito mais em insinuações e hipóteses... ainda reclama pesquisas exaustivas.” (LAPA, 1996, p. 166). Certamente, as pesquisas de Fragoso surgiram a contento das reivindicações de Amaral Lapa.

\title{
Considerações finais
}

Enfim, considerando todos os trabalhos supracitados, sobretudo àqueles que marcam modelos explicativos antagônicos sobre a dinâmica de funcionamento da economia colonial, compreendemos que eles trazem consigo um caráter muito mais de complementaridade do que de contradição. Os autores da chamada "Escola do Sentido

\footnotetext{
${ }^{23}$ Em 1973, José Roberto do Amaral Lapa publicou o livro "Economia Colonial” e, cerca de uma década depois, produziu a obra "O Antigo Sistema Colonial”. Em 1991, escreveu "O Sistema Colonial". Em todos esses trabalhos, o autor dedica-se a entender a questão do mercado interno e de seus desdobramentos como, por exemplo: a economia de subsistência e o comércio inter-regional.
} 
da Colonização" não negam a existência de um mercado interno, conforme podemos observar a partir de um fragmento de texto de Fernando Novais:

E claro que ao lado dessa produção essencial para o mercado europeu, organizava-se nas colônias todo um setor, dependente do primeiro, da produção que visava a suprir a subsistência interna, daquilo que não podia ser aprovisionado na metrópole [...] Nos períodos em que a procura externa se retraia, isto é, quando baixavam os preços europeus dos produtos coloniais, as unidades produtoras na colônia tendiam a deslocar fatores para a produção de subsistência, pois diminuía sua capacidade de importar, quando, ao contrário, ampliava-se a procura externa, as unidades produtivas coloniais tendiam a mobilizar todos os fatores na produção exportadora; abria-se, então, à economia colonial de subsistência a possibilidade desenvolver-se autonomamente (NOVAIS, 1989, p. 96).

Em uma outra passagem, Fernando Novais diz:

As economias coloniais, em que resulta afinal a expansão ultramarina, acabam por configurar, encaradas globalmente no contexto da economia mundial, setores produtivos especializados enquadrados nas grandes rotas comerciais, e pois mercados consumidores em expansão (NOVAIS, 1989, p. 97).

Assim como os autores da chamada "Escola do Rio" não refutam a capacidade de estímulo do mercado externo frente à economia colonial, como se pode observar a seguir:

\footnotetext{
O sistema agrário escravista-exportador [...] passava a ser entendido como resultado do processo de reprodução de uma economia mais complexa do que a apresentada pelos modelos explicativos, presentes na historiografia. Com isso, não queremos dizer que a economia considerada não fosse escravista e exportadora (esses são os laços estruturais mais amplos) e nem que ela estivesse subjugada às conjunturas do mercado internacional. Entretanto, para além desses traços, a economia colonial tinha outras características estruturais. Possuía outras formas de produção (ao lado da escravista) e um mercado interno, espaço no qual se realizariam acumulações endógenas (FRAGOSO, 1992, p. 26-27).
}

Nesse caso, as distinções entre esses trabalhos devem ser observadas muito mais em termos de enfoque, abordagem e objeto de análise. Os primeiros estão mais preocupados com análises macroestruturais, a exemplo do papel do Brasil e de Portugal na formação do capitalismo, a relação entre as metrópoles e as suas respectivas colônias ou as diferentes formas de colonização nos territórios ultramarinos. Os segundos centram sua análise na investigação endógena da própria economia colonial, buscando entender o seu funcionamento, via de regra, a partir de estudos empíricos regionais. Dessa forma, percorrendo caminhos metodológicos distintos, chegam a resultados 
igualmente distintos, ainda que não menos importantes para o entendimento da dinâmica da economia brasileira no período colonial de sua história.

\section{REFERÊNCIAS}

ALGRANTI, Leila Mezan. O Feitor Ausente. (estudo sobre a escravidão urbana no Rio de Janeiro, 1808-1821.1 ed. Petrópolis: Vozes, 1988.

ARRUDA, José Jobson de Andrade. O Brasil no comércio colonial. São Paulo: Ática, 1980.

BARICKMAM, B. J. Um Contraponto baiano: açúcar, fumo, mandioca e escravidão no Recôncavo, 1789-1860. Rio de Janeiro. Ed. Civilização Brasileira, 2003.

CARDOSO, C.F.S. Escravo Ou Camponês? O Proto-Campesinato Negro Nas Américas. São Paulo: Brasiliense, 1987. 
CARDOSO, C.F.S. O trabalho na América Latina Colonial. São Paulo: Ática, 1985.

CARDOSO, C.F.S. A Afro-América: a escravidão no Novo Mundo. Rio de Janeiro: Graal, 1981.

CARDOSO, C.F.S. Agricultura, Escravidão e Capitalismo. Petrópolis: Vozes, 1979.

CARDOSO, Fernando Henrique. Capitalismo e Escravidão no Brasil Meridional: o negro na sociedade escravocrata do Rio Grande do Sul. São Paulo: DIFEL, 1962.

CHALHOUB, Sidney. Visões da Liberdade: uma história das últimas décadas da escravidão na Corte. São Paulo: Companhia das Letras, 1990.

CHALHOUB, Sidney. Condições sociais de Industrialização. Revista Brasiliense, $\mathrm{n}^{\circ}$ 28, 1961.

COSTA, Emília Viottida. Da monarquia à república: momentos decisivos. $3^{\circ}$ edição. São Paulo: Brasiliense, 1985.

FARIA, S. S. C. A colônia em movimento: fortuna e família no cotidiano colonial. 1. ed. Rio de Janeiro: Nova Fronteira, 1998.

FLORENTINO, Manolo; FRAGOSO, João Luís Ribeiro. Arcaísmo como Projeto: Mercado atlântico, sociedade agrária e elite mercantil em economia colonial tardia, Rio de Janeiro, c. 1790 -c. 1840. Rio de Janeiro: Civilização Brasileira, 2001.

FRAGOSO, J. L. R. Homens de grossa aventura: acumulação e hierarquia na praça mercantil do Rio de Janeiro (1790-1830). 1. ed. Rio de Janeiro: Arquivo Nacional, 1992.

FRAGOSO, J. L. R. Modelos explicativos da chamada economia colonial e a ideia de Monarquia Pluricontinental: notas de um ensaio. História (São Paulo) v.31, n.2, p. 106-145, jul/dez 2012.

FERLINI, Vera Lúcia Amaral. Pobres do açúcar: estrutura produtiva e relações de poder no nordeste colonial. In: SZMERECSÁNIY, Tamás (Org.). História Econômica do período colonial. 2 ed. revista. São Paulo: Hucitec/ABPHE/Edusp/Imprensa Oficial, 2002.

FERNANDES, Florestan. Circuíto Fechado: quatro ensaios sobre o "Poder Institucional”. São Paulo: HUCITEC, 1976.

FURTADO, Celso. Formação Econômica do Brasil. 13. Ed. São Paulo, Editora Nacional, 1975.

GAMA, Lana Lage. Rebeldia negra e abolicionismo. Rio de Janeiro: Achiame, 1980. 
GIL, T. L.. Os Infiéis transgressores: elites e contrabandistas nas fronteiras do Rio Grande e do Rio Pardo (1760-1810). Rio de Janeiro: Arquivo Nacional, 2007.

GODELIER, Maurice. Horizontes da Antropologia. Lisboa: Edições 70, s/d.

GORENDER, Jacob. O Escravismo Colonial. 6ª ed. São Paulo: Ática, 1992.

IANNI, Octávio. As metamorfoses do escravo: apogeu e crise da escravatura no Brasil Meridional. São Paulo, Ed. Difusão Européia do Livro, 1962.

KELMER MATHIAS, C. L. As múltiplas faces da escravidão: o espaço econômico do ouro e sua elite pluriocupacional na formação da sociedade mineira setecentista, c. 1711 - c. 1756. 1. ed. Rio de Janeiro: Mauad X: FAPERJ, 2012.

LARA, Silvia Hunold. Campos de violência: Escravos e Senhores na Capitania do Rio de Janeiro, 1750-1808. Rio de Janeiro: Paz e Terra, 1988.

LAPA, José Roberto do Amaral. Economia Colonial. São Paulo: Perspectiva, 1973.

LAPA, José Roberto do Amaral. O Antigo Sistema Colonial. Coleção Primeiros vôos, vol 8. São Paulo: Brasiliense, 1982.

LAPA, José Roberto do Amaral. O Sistema Colonial. Série Princípios, vol. 209. São Paulo: Ática, 1991

LAPA, José Roberto do Amaral. O interior da estrutura. In: SZMRECSÁNYI, Tamás (Org.). História Econômica do período colonial. São Paulo: Hucitec- FAPESP, 1996.

LINHARES, Maria Yedda Leite. História do Abastecimento - uma problemática em questão, 1530-1918. Brasília: Biblioteca Nacional de Agricultura, 1979.

LINHARES, Maria Yedda Leite; SILVA, Francisco Carlos Teixeira da. História da Agricultura Brasileira - Combates e Controvérsias. São Paulo: Editora Brasiliense, 1981.

LINHARES, Maria Yedda Leite; SILVA, Francisco Carlos Teixeira da. História Política do Abastecimento (1918-1974). Brasília: Biblioteca Nacional de Agricultura, 1979.

MACHADO, Maria Helena Pereira Toledo. Crime e escravidão. Trabalho, luta e resistência nas lavouras paulistas 1830-1888.1 ed. São Paulo: Brasiliense, 1987.

MARX, Karl. A Chamada Acumulação Primitiva. In: MARX, Karl. O Capital. Tomo II, Capítulo XXIV. São Paulo: Ed. Nova Cultural, 1996.

MARX, Karl. Contribuição a crítica da economia política. $2^{a}$ ed. São Paulo: Expressão Popular, 2008.

MATTOS, Hebe. Ao Sul da História: lavradores pobres na crise do trabalho escravo. São Paulo: Brasiliense, 1987. 
MELlO, João Manuel Cardoso de. O Capitalismo Tardio. São Paulo: Brasiliense, 1982.

MINTZ, S. W. Caribbean Transformations. Chicago: Aldine, 1974. p.146-56.

MINTZ, S. W. O poder amargo do Açúcar. Recife: Editoria Universitária, 2003.

MINTZ, S. W. Slavery, Colonialism and Racism. New York: W.W. Norton, 1996.

MINTZ, S. W. Sweetness and Power: The Place of Sugar in Modern History. New York: Viking-Penguin, 1985.

NOVAIS, Fernando Antonio. Portugal e Brasil na Crise do Antigo Sistema Colonial.

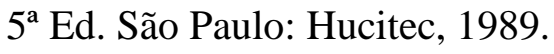

PESAVENTO, Fábio. Um pouco antes da Corte: a economia do Rio de Janeiro na segunda metade do setecentos.1. ed. Jundiaí: Paco Editorial, 2013.

PRADO JR., Caio. Formação do Brasil Contemporâneo. 15 ${ }^{a}$ Ed. São Paulo: Brasiliense, 1977.

QUEIRÓS, Suely Robles Reis de. Escravidão negra em São Paulo: um estudo das tensões provocadas pelo escravismo no século XIX. Rio de Janeiro: José Olympio, 1977.

REIS, João José. Rebelião escrava no Brasil. A história do levante dos malês (1835). 1 ed: São Paulo: Brasiliense, 1986.

RIBEIRO, Alexandre Vieira. A Cidade de Salvador: estrutura econômica, comércio de escravos, grupo mercantil (c.1750-c.1800). 2009. Tese (Doutorado em História Social) Universidade Federal do Rio de Janeiro.

SAMPAIO, Antonio Carlos Jucá de. Na encruzilhada do império: hierarquias sociais e conjunturas econômicas no Rio de Janeiro (c.1650 - c.1750). 1. ed. Rio de Janeiro: Arquivo Nacional, 2003.

SERENI, Emilio. La Categoria de "Formación econômica y social. In: LUPORINI, Cesare\& SERENI. El concepto de formación econômico-social. $3^{\text {a }}$ Ed. México, Cuadernos do Pasado y Presente (39), 1978.

SLENES, Robert Wayne Andrew. Na Senzala, Uma Flor: Esperanças e Recordações Na Formação da Família Escrava (Brasil Sudeste, Século XIX). Rio de Janeiro - RJ: Nova Fronteira, 1999.

SOUZA, Laura de Mello e. Desclassificados do ouro: a pobreza mineira no século XVIII.1. ed. Rio de Janeiro: Graal, 1983. 
Eduardo Jose Santos Borges; Augusto Fagundes da Silva dos Santos 